\title{
Bowel function measurements of individuals with different eating patterns
}

\author{
G J DAVIES, M CROWDER, B REID, AND J W T DICKERSON \\ From the Department of Biochemistry, Division of Nutrition and Food Science, University of Surrey, \\ Guildford, Surrey, and Department of Radiology, Kingston Hospital, Kingston, Surrey
}

SUMMARY Bowel function was assessed in 51 subjects: 10 women and seven men who habitually consumed an omnivorous, vegetarian, or vegan diet. The subjects on these diets had a mean intake of fibre of $23 \mathrm{~g}, 37 \mathrm{~g}$, and $47 \mathrm{~g}$ respectively. Mean transit times were variable and not significantly different between the groups. Vegans, however, had a greater frequency of defecation and passed softer stools. All measurements of bowel function were significantly correlated with total dietary fibre. As dietary fibre increased mean transit time decreased, stool frequency increased and the stools became softer. Men produced a greater quantity of softer, less formed faeces than women. During the luteal phase of the menstrual cycle women excreted harder stools and had a significantly longer mean transit time. The finding that mean transit time was more highly correlated with faecal form than any of the other bowel function measurements could be of practical importance.

That differences in bowel function exist between people consuming different diets has been reported by several investigators. In comparison with omnivores, vegetarians have been reported to have a shorter transit time, ${ }^{123}$ a greater frequency of defecation ${ }^{45}$ and to pass a larger amount of faeces daily. ${ }^{126}$

Critical examination of the methodologies used in these various studies, however, limits interpretation of the results in relation to the 'dietary fibre hypothesis'. For example, duration of diet was not always stated ${ }^{5}$ and dietary fibre intake was only measured in one of the studies. ${ }^{3}$ In two of the studies the health of subjects was uncertain. ${ }^{14}$ The sex distribution was either not stated, ${ }^{6}$ or uneven $^{345}$ and in one of the studies all the subjects were men. ${ }^{2}$ The exact age distribution was not certain in some of the studies ${ }^{13}$ and the age ranges differed markedly in Holm and Hansen's ${ }^{2}$ subjects. The period of time for which stools were collected in relation to specific measurements of bowel function was probably satisfactory in only three of the studies. ${ }^{1-3}$ The method used for the measurement of transit time in two of the studies has been superseded $^{12}$ and of possible significance is the fact that none of the studies took account of stool consistency

Address for correspondence: Professor J W T Dickerson, Department of Biochemistry, University of Surrey, Guildford, Surrey GU2 5XH. Received for publication 3 June 1985 or faecal form. Only two of the studies were undertaken in the United Kingdom, ${ }^{13}$ so that geographical factors may limit interpretation.

An attempt has been made in the present study to overcome the major uncertainties outlined above.

\section{Methods}

SUBJECTS

The subjects were all free from overt symptoms of disease, none had undergone major surgery during the preceding six months and none were pregnant or lactating. All subjects were accustomed to their diets. Omnivores had been so for life and the vegetarians and vegans had followed their respective diets for $31 \%$ (range 3-35\%) and 15\% (range $1-41 \%$ ) of their lives respectively. Most of the vegans had been vegetarians previously. There were 10 women and seven men in each dietary group. The mean ages of the omnivores, vegetarians, and vegans were 35 years (range 11-56 years), 34 years (range $10-71$ years) and 31 years (range 5-63 years) respectively. Most of the subjects were in social class $2 .^{7}$ Menstruating women recorded the stage they were at in the menstrual cycle throughout the survey. This was done as a precaution with specific reference to the findings of Rees and Rhodes ${ }^{8}$ although no attempt was made to match subjects in respect of this variable.

Dietary fibre intakes were calculated from 
weighed food intakes measured over seven consecutive days. ${ }^{9}$ All stools passed during the dietary survey week were collected. The collection period was extended if necessary for the measurement of transit time. Wyman and his colleagues ${ }^{10}$ commented upon the extraordinary variation in the size of individual stools and emphasised the need for several days collection for meaningful results.

Each subject was provided with a 'stool collection kit'.

The kit comprised: (i) plastic sealable selfadhesive sling bags for the collection of individual stools; (ii) plastic air-tight stack-a-boxes, with a 2.5 litre capacity carrying a label with the words subject number, day, date, and time, typed thereon and space for filling in the necessary details. These containers were used to accommodate one stool only, this reduced the risk of specimens becoming squashed during the collection period; (iii) a zipped plastic wallet containing written instructions for collecting faeces and a pen for the recording operation; (iv) a fresh air spray to minimise the problem of odour inherent in the collection of stools that are not passed into water; (v) a plastic dustbin bag labelled 'specimens' used for storing the used stack-a-boxes; (vi) a light weight haversack type bag, with the capacity to accommodate two stack-aboxes and primary collection bags the folder and fresh air spray, for the collection of stools away from home.

To collect an individual stool a primary collection bag was attached to the rear of the toilet aperture. The bag was used to collect faeces only and it was then promptly sealed and placed in an upright position, inside the secondary container, by means of a handle formed from the flaps of the sling. The box was sealed and the label completed. The specimens were collected every other day from subjects' homes.

Frequency of defecation was calculated from the dates and times stools were passed, and recorded on the lid of the secondary container.

The mean weight of faeces passed per day was obtained from the sum of the weights of the individual collections. The weights of the individual motions were obtained on a hook type spring balance weighing up to $500 \mathrm{~g} \pm 5 \mathrm{~g}$. Allowance was made for the weight of the hook.

Faeces were classified according to their appearance and a linear scale drawn up. This is shown in Table 1.

The mean form of faeces was calculated according to the formula $\mathrm{fx} / \mathrm{n}$ where:

$f=$ number of times faecal form was observed

$\mathrm{x}=$ form of faeces according to linear scale

$\mathrm{n}=$ total number of faecal forms observed.
Table 1 Form of faeces

\begin{tabular}{|c|c|}
\hline $\begin{array}{l}\text { Linear } \\
\text { scale no }\end{array}$ & Form of faeces \\
\hline 1 & Loose, watery and runny \\
\hline 2 & Mushy, flattened surface and definite flow \\
\hline 3 & Mushy, heaped surface \\
\hline 4 & Collapsed, remnants of original shape visible \\
\hline 5 & $\begin{array}{l}\text { Snake-like, coiled or cylindrical with a } \\
\text { smooth surface }\end{array}$ \\
\hline 6 & Cylindrical with superficial cracks \\
\hline 7 & Cylindrical with deep cracks \\
\hline 8 & $\begin{array}{l}\text { Fragmented/segments; pellets like sheep } \\
\text { droppings; corrugated formations and button } \\
\text { like discs }\end{array}$ \\
\hline
\end{tabular}

Stool rheology was determined by measuring stool consistency as described by Exton-Smith and his colleagues ${ }^{11}$ with some modifications. This involved measuring the degree of penetration into the stool of a cone of standard weight in a given time.

The Seta (1700) Universal penetrometer was used in preference to the (1710) standard model because it had a fine adjustment wheel which allowed for greater precision in positioning the tip of the cone on the surface of the sample.

The 1800 (ASTM-IP) standard cone was substituted by a smaller one, the 1791 quarter scale cone. This was necessary because of the variety of stools being examined. Unformed stools, particularly faecal form 3 tended to have hilly-like ridges. This type of stool topography caused the cone to tilt, thus affecting the angle of penetration into the sample. An important factor in view of the fact that the cone angle is crucial to the reading. ${ }^{12}$ Moreover, the larger cone was too big for use on small stools.

The total moving weight of the cone and plunger of $150 \mathrm{~g}$ as used by Exton-Smith and his colleagues ${ }^{11}$ was reduced to $9.38 \mathrm{~g}$. Weight reduction was brought about by using a light weight plunger, omitting the lead shot altogether in addition to the smaller cone. This was necessary because the stools examined were not as firm as those examined by the authors of the method and the limiting factor to the distance travelled by the moving weight was the depth of the stool as opposed to the degree of hardness.

Exton-Smith et $a^{11}$ took readings along the length of the stool. The variety of faecal forms, however, necessitated the taking of a scatter of readings in the majority of samples. Measurements were not taken on loose pellets or other small faecal units because readings were of displacement rather than penetration. This could lead to bias in the results for those subjects who frequently pass stools in this form.

The penetration of the stool was expressed in 
units of $0.1 \mathrm{~mm}^{11}$ and the mean value calculated from the number of stools passed.

Mean transit time was measured according to the method of Cummings et $^{a l^{13}}$ with some modifications to the radiographic procedure. The subjects took 20 radio-opaque barium sulphate impregnated polyethylene pellets of clearly distinguishable shape on each of three consecutive days. Stools passed after the ingestion of markers were radiographed until the markers had been recovered. The use of three different shapes of markers in the same subject permitted three measurements of transit time to be made. The values given in the results were calculated from the mean of these three measurements in each subject.

The primary collection bags were resealed, folded, flattened and labelled using the labels on the lid of the secondary container. The stools were radiographed and the different shaped markers counted on the individual specimens. Previous flattening of the samples prevented superimposition of markers.

To radiograph faeces a tray was placed directly on top of a $35 \times 42.5 \mathrm{~cm}$ cassette. The latter used Fast Tungstate Screens and contained a Kodak XRPI film. The specimens and identification number were well within the periphery of the cassette. The x-ray tube was positioned at a focus film distance of 100 $\mathrm{cm}$. Exposure factors were $55 \mathrm{kV} ; 100 \mathrm{~mA}$ and 0.06 sec. The tube had a $1.2 \mathrm{~mm}$ focal spot. The films were processed using a Kodak M6AL, $90 \mathrm{sec}$ Xomat.

\section{Results}

The mean daily intakes of dietary fibre for omni-

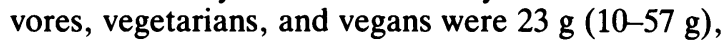
$37 \mathrm{~g}(15-71 \mathrm{~g})$, and $47 \mathrm{~g}(24-78 \mathrm{~g})$ respectively. Transit times were very variable in each of the dietary groups (Table 2) and because of this, differences in mean values were not statistically significant. In comparison with omnivores, vegans had a slightly shorter mean transit time. Frequency of defecation was significantly greater $(p<0.01)$; the quantity of faeces passed daily increased $(\mathrm{p}<0.02)$; the stools were softer as shown by the higher penetrometer readings $(p<0.02)$ and faeces tended to be midway between semi and smoothly formed $(p<0 \cdot 01)$ as opposed to cylindrical with superficial cracks. As the large standard deviations and ranges show there was, however, considerable individual variation.

All the parameters of bowel function were significantly correlated with total dietary fibre intake and that obtained from various food sources (Table 3 ). As dietary fibre intakes increased mean transit time decreased; stool frequency increased; there was an increase in the daily faecal wet weight and stools became softer and veered towards the lower end of the faecal form scale. The highest correlation coefficient for all the bowel function parameters was obtained with total dietary fibre intake, but the differences were small, particularly in relation to fibre derived from cereals and vegetables.

In comparison with women, men produced a significantly $(p<0.001)$ greater quantity of faeces daily (149 \pm 48 and $229 \pm 96 \mathrm{~g}$ respectively). The stools were significantly $(\mathrm{p}<0.01)$ softer with mean rheologies of $37 \pm 19$ and $54 \pm 250.1 \mathrm{~mm}$ respectively. Women tended to produce a significantly $(\mathrm{p}<0.02)$ more formed stool than men, $5.5 \pm 1.4$ and $4 \cdot 5 \pm 1 \cdot 3$ respectively.

In view of the differences between the sexes, women were classified according to whether they were (a) taking oral contraceptives, (b) in the luteal phase of the menstrual cycle, or (c) premenstruating, postmenopausal or in other endocrinological phases of the menstrual cycle. A comparison of bowel function measurements in the three categories is shown (Table 4). There was little difference between categories (a) and (c). The differences between categories (b) and (c) on the other hand were more illuminating. Women in the luteal phase of the menstrual cycle had a significantly $(p<0.001)$

Table 2 Bowel function measurements in omnivores, vegetarians, and vegans

\begin{tabular}{|c|c|c|c|c|c|c|}
\hline $\begin{array}{l}\text { Dietary } \\
\text { group }\end{array}$ & & $\begin{array}{l}\text { Mean transit } \\
\text { (time) }\end{array}$ & $\begin{array}{l}\text { Frequency of } \\
\text { defecation } / 24 h\end{array}$ & $\begin{array}{l}\text { Wet weight of } \\
\text { faeces }(g / 24 h)\end{array}$ & $\begin{array}{l}\text { Mean rheology } \\
\text { of stools }(0.1 \mathrm{~mm})\end{array}$ & $\begin{array}{l}\text { Mean form of } \\
\text { faeces }(1-8)\end{array}$ \\
\hline Omnivorous & $\begin{array}{l}\text { Mean and SD } \\
\text { Range }\end{array}$ & $\begin{array}{l}51 \cdot 8 \pm 19 \cdot 4 \\
32 \cdot 5-107 \cdot 9\end{array}$ & $\begin{array}{l}1 \cdot 0 \pm 0 \cdot 2 \\
0 \cdot 7-1 \cdot 3\end{array}$ & $\begin{array}{r}153 \pm 79 \\
54-415\end{array}$ & $\begin{array}{l}35 \pm 22 \\
11-87\end{array}$ & $\begin{array}{l}5 \cdot 7 \pm 1 \cdot 3 \\
2 \cdot 8-7 \cdot 5\end{array}$ \\
\hline Vegetarian & $\begin{array}{l}\text { Mean and SD } \\
\text { Range }\end{array}$ & $\begin{array}{l}48 \cdot 5 \pm 27 \cdot 2 \\
28 \cdot 3-146 \cdot 1\end{array}$ & $\begin{array}{l}1 \cdot 2 \pm 0 \cdot 5 \\
0 \cdot 4-2 \cdot 1\end{array}$ & $\begin{array}{r}168 \pm 56 \\
81-265\end{array}$ & $\begin{array}{r}44 \pm 26 \\
8-104\end{array}$ & $\begin{array}{l}5 \cdot 0 \pm 1 \cdot 5 \\
3 \cdot 0-7 \cdot 8\end{array}$ \\
\hline Vegan & $\begin{array}{l}\text { Mean and SD } \\
\text { Range }\end{array}$ & $\begin{array}{l}44 \cdot 7 \pm 21 \cdot 0 \\
28 \cdot 9-101 \cdot 6\end{array}$ & $\begin{array}{l}1 \cdot 7 \pm 0 \cdot 9 \ddagger \\
0 \cdot 6-4 \cdot 4\end{array}$ & $\begin{array}{l}225 \pm 91 \dagger \\
129-499\end{array}$ & $\begin{array}{l}52 \pm 18 \dagger \\
24-91\end{array}$ & $\begin{array}{l}4 \cdot 5 \pm 1 \cdot 2 \ddagger \\
2 \cdot 3-7 \cdot 1\end{array}$ \\
\hline
\end{tabular}

Values significantly different from those in omnivores are shown.

* when $\mathrm{p}<0.05 ; \dagger$ when $\mathrm{p}<0.02 ; \ddagger$ when $\mathrm{p}<0.01$, and $\S$ when $\mathrm{p}<0.001$. 
Table 3 The inter-relationship of dietary fibre from various food sources with measures of bowel function (correlation coefficient $)^{*}$

\begin{tabular}{|c|c|c|c|c|c|}
\hline Fibre & $\begin{array}{l}\text { Mean transit } \\
\text { time }(h)\end{array}$ & $\begin{array}{l}\text { Frequency of } \\
\text { defecation } / 24 h\end{array}$ & $\begin{array}{l}\text { Wet weight of } \\
\text { faeces }(g / 24 h)\end{array}$ & $\begin{array}{l}\text { Mean rheology of } \\
\text { stools }(0.1 \mathrm{~mm})\end{array}$ & $\begin{array}{l}\text { Mean form of } \\
\text { faeces }(1-8)\end{array}$ \\
\hline Total & -0.76 & +0.87 & +0.96 & +0.90 & -0.81 \\
\hline Cereal & -0.74 & +0.81 & +0.93 & +0.87 & -0.79 \\
\hline Vegetable & -0.74 & $+0 \cdot 81$ & +0.87 & +0.82 & -0.79 \\
\hline Fruit & -0.56 & +0.75 & +0.78 & +0.72 & -0.60 \\
\hline Nut & -0.53 & +0.72 & $+0 \cdot 70$ & +0.68 & -0.54 \\
\hline
\end{tabular}

${ }^{*} \mathrm{p}<0.001$ for all the correlations quoted.

longer mean transit time. Stools were significantly $(\mathrm{p}<0.05)$ harder and veered towards the upper limit of faecal form $(\mathrm{p}<0 \cdot 02)$.

One subject progressed from day 28 of her cycle to day 5 and changes in bowel function were evident (Table 5). None of the radio opaque markers appeared in this subject's stools until day two of the cycle - that is four days after the ingestion of the first dose of markers. Until this time the stools were light in weight, hard and fragmented. Thereafter and until day four of the cycle stool wet weight increased and the faeces were softer and even flowed. Transit time as determined from single doses of marker decreased progressively from doses 1 to 3 with measured transit time of $81.4,57 \cdot 2$, and 44.2 hours respectively.

There was no significant association between any of the bowel function measurements and age. Although, it was noted that subjects aged between $14-45$ had a mean transit time of approximately $1 / 2$ a day longer than either younger or older subjects.

There was considerable variation in the same individual in the form of faeces. Stools ranged from runny to fragmented (forms 1 and 2 and 8 respectively). Moreover, differences in faecal form were also observed in faeces from the same bowel movement (Table 5).

Mean transit time was significantly correlated with the other measurements of bowel function $(p<0.001)$. As mean transit time decreased stool frequency and faecal wet weight increased $(r+0.75$ and +0.76 respectively). Stools softened $(r+0.72)$ and tended to be less well formed $(r+0 \cdot 93)$.

\section{Discussion}

In general terms our results support and extend those of others. ${ }^{1-6}$

The differences in bowel function according to the degree of vegetarianism are in accord with our previously reported finding ${ }^{9}$ that vegetarians and vegans especially had significantly higher intakes of dietary fibre than omnivores. Moreover, it is likely that some of the individual variation in bowel function might be accounted for by the individual differences in dietary fibre intake.

The link between dietary fibre intake and bowel function is substantiated by the fact that total dietary fibre intake and fibre derived from the various food sources was highly correlated with the different measures of bowel function.

Of possible significance is the finding that the differences between the correlation coefficients between total dietary fibre and fibre derived from cereals and vegetables with the bowel function variables measured were small. Much emphasis has already been placed upon the effect of cereal fibre on bowel function and there is a growing interest in the role of fibre derived from pulses. Leeds $e^{2}$ al $^{14}$ have shown that diets rich in haricot beans increase

Table 4 Parameters of bowel function in women in relation to the use of oral contraceptives and the luteal phase in the menstrual cycle (mean and standard deviation)

\begin{tabular}{lllll}
\hline $\begin{array}{l}\text { Category of } \\
\text { woman }(\mathrm{no})\end{array}$ & $\begin{array}{l}\text { Mean transit } \\
\text { time }(\mathrm{h})\end{array}$ & $\begin{array}{l}\text { Frequency of } \\
\text { defecation/24 } h\end{array}$ & $\begin{array}{l}\text { Wet weight of } \\
\text { faeces }(\mathrm{g} / 24 \mathrm{~h})\end{array}$ & $\begin{array}{l}\text { Mean rheology of } \\
\text { stools }(0 \cdot 1 \mathrm{~mm})\end{array}$ \\
\hline a 7 & $43 \cdot 9 \pm 5 \cdot 0$ & $1 \cdot 2 \pm 0 \cdot 4$ & $172 \pm 36$ & $34 \pm 16$ \\
b 6 & $94 \cdot 9 \pm 32 \cdot 48$ & $1 \cdot 0 \pm 0 \cdot 2$ & $119 \pm 26$ & $23 \pm 14^{*}$ \\
c 17 & $42 \cdot 3 \pm 10 \cdot 9$ & $1 \cdot 6 \pm 0 \cdot 9$ & $150 \pm 55$ & $43 \pm 19$ \\
\hline
\end{tabular}

a Taking oral contraceptives. b In the luteal phase of the menstrual cycle.

c Premenstruating, post menopausal or not in the luteal phase of the menstrual cycle.

Significance of values in the luteal phase compared with those in the premenstruating etc phase shown as in Table 2 . 
Table 5 Bowel function measurements of one female during the menstrual cycle

\begin{tabular}{|c|c|c|c|c|}
\hline $\begin{array}{l}\text { Menstrual } \\
\text { cycle } \\
\text { (day) }\end{array}$ & $\begin{array}{l}\text { Markers } \\
\text { excreted } \\
\text { (no) }\end{array}$ & $\begin{array}{l}\text { Wet } \\
\text { weight of } \\
\text { faeces } / 24 h\end{array}$ & $\begin{array}{l}\text { Mean } \\
\text { rheology of } \\
\text { individual } \\
\text { stools } \\
(0.1 \mathrm{~mm})\end{array}$ & $\begin{array}{l}\text { Form of faeces } \\
\text { observed } \\
\text { per bowel } \\
\text { action }(1-8)\end{array}$ \\
\hline \multicolumn{5}{|l|}{28} \\
\hline 29 & & 50 & 16 & 8 \\
\hline 1 & & 70 & 15 & 8 \\
\hline 2 & 40 & 310 & 67 & 2 \\
\hline 3 & 10 & 50 & 49 & 2 \\
\hline 4 & 10 & 180 & 42 & 2 \\
\hline 5 & & 95 & 11 & 8 \\
\hline
\end{tabular}

No stools were passed on day 28 of the cycle and one motion was passed daily on each of the other days on which measurements were made.

stool frequency and faecal wet weight. The high intake of pulses by vegetarians and vegans has already been reported in our previous article. ${ }^{9}$ It would seem that fibre from vegetables, particularly pulses, is worthy of further investigation. Moreover, it may be that in some way the 'mixture' of fibres may be of more relevance to bowel function than specific fibre fractions.

The differences in bowel function between men and women are probably accounted for to some extent by differences in fibre intake between the sexes. ${ }^{9}$ The further observation that menstruating women had bowel function measurements that correlated with different endocrinological phases in the menstrual cycle would suggest that this factor could be of some importance. The differences in bowel function associated with the luteal phase of the cycle may be related to increased progesterone concentrations. ${ }^{15}$ Christofides et al $^{16}$ have suggested that progesterone causes the inhibition of the gut-stimulatory hormone motilin. This hormone has powerful effects on the smooth muscle of the gastric antrum, duodenum, and colon. ${ }^{17}$

The observations made on bowel function in the subject who progressed from day 28 of her cycle to day five are comparable with those of others. ${ }^{814} 15$ Rees and Rhodes ${ }^{8}$ have attributed the formation of loose motions at this stage in the menstrual cycle to the release of prostaglandins $E_{2}$ and $F_{2 \alpha}$. Unduly high quantities of prostaglandins $E_{2}$ and $F_{2 \alpha}$ are synthesised by the endometrial tissue during menstruation. ${ }^{18}$

The importance of these findings is unknown, but if women are prone to alterations in bowel function during different phases of the menstrual cycle the observations made seriously question irritable bowel syndrome diagnosis when emphasis is placed upon variations in bowel function. ${ }^{19}$ It is also possibly of some significance that this syndrome is said to be more common in women. The suggestion that oral contraceptives may induce constipation in susceptible women ${ }^{20}$ was not substantiated in this study.

The lack of statistical association between bowel function measurements and age is in accord with the findings of Gear and his colleagues. ${ }^{3}$

The importance of the differences in faecal form is uncertain. It may be that they reflect variations in the norm for different individuals. They may be construed to support the statement:

'To understand the disorders of bowel motility, it is important to know the range of bowel patterns in the general population' ${ }^{19}$

The finding that mean transit time was more highly correlated with faecal form than any of the other bowel function measurements could be of practical importance. The simple observation of faecal form might allow clinically useful information to be inferred with regard to transit time. Slavin et $a l^{21}$ have in fact stated 'Correlations between transit time and other measures of bowel function, that are simpler to determine, suggest it may be possible to predict transit time from one or more of these measures'.

\section{References}

1 Burkitt DP, Walker ARP, Painter NS. Effect of dietary fibre on stools and transit-times, and its role in the causation of disease. Lancet 1972; 2: 1408-12.

2 Holm CN, Hansen LP. Plantefibre og gastarointestinal passagetid. Ugeskr Laeg 1975; 137: 561-5. Translated by Helena Berglund-Perry.

3 Gear JSS, Brodribb AJM, Ware A, Mann JI. Fibre and bowel transit times. Br J Nutr 1981; 45: 77-82.

4 Goldberg MJ, Smith JW, Nichols RL. Comparison of the fecal microflora of Seventh-Day Adventists with individuals consuming a general diet. Ann Surg 1977; 186: $97-100$.

5 Kuhnlein U, Bergstrom D, Kuhnlein H. Mutagens in feces from vegetarians and non-vegetarians. Mutat Res 1981; 85: 1-12.

6 Miettinen TA, Tarpila S. Fecal $\beta$-sitosterol in patients with diverticular disease of the colon and in vegetarians. Scand J Gastroenterol 1978; 13: 573-6.

7 Central statistical office social trends no. 6. London: HMSO, 1975.

8 Rees WDW, Rhodes J. Altered bowel habit and menstruation. Lancet 1976; 2: 475.

9 Davies GJ, Crowder M, Dickerson JWT. Dietary fibre intake of individuals with different eating patterns. $J$ Hum Nutr Appl 1985; 39A: 139.

10 Wyman JB, Heaton KW, Manning AP, Wicks ACB. Variability of colonic function in healthy subjects. Gut 1978; 19: 146-50.

11 Exton-Smith AN, Bendall MJ, Kent F. A new techni- 
que for measuring the consistency of faeces: a report on its application to the assessment of Senokot therapy in the elderly. Age Ageing 1974; 3: 1-3.

12 Muller HG. An introduction to food theology. London: Heinemann, 1973.

13 Cummings JH, Jenkins DJA, Wiggins HS. Measurement of the mean transit time of dietary residue through the human gut. Gut 1976; 17: 210-8.

14 Leeds AR, Khumalo TD, Ndaba NG, Lincoln D. Haricot beans, transit time and stool weight. J Pl Fds 1982; 4: 33-41.

15 Wald A, Van Thiel DH, Hoechstetter L et al. Gastrointestinal Transit: the effect of the menstrual cycle. Gastroenterology 1981; 80: 1497-1500.

16 Christofides ND, Ghatei MA, Bloom SR, Borberg C, Gillmer MDG. Decreased plasma motilin concentra- tions in pregnancy. $\mathrm{Br}$ Med J 1982; 285: 1453-4.

17 Christofides ND. Importance of the jejunal hormone motilin. In: Walters G, Bloom SR, eds. Gastrointestinal and related hormones. London: British Medical Association, 1978: 51-7.

18 Gonzalez ER. New era in treatment of dysmenorrhea. JAMA 1980; 244: 1885-6.

19 Drossman DA, Sandler RS, McKee DC, Lovitz AJ. Bowel patterns among subjects not seeking health care. Gastroenterology 1982; 83: 529-34.

20 Read NW. Drug-induced constipation. MIMS January 1983: 19-21.

21 Slavin JL, Sempos CT, Brauer PM, Marlett JA. Limits of predicting gastrointestinal transit time from other measures of bowel function. Am J Clin Nutr 1981; 34: 2111-6. 